\title{
Análise do desempenho de fornecedores de uma empresa de manufatura apoiada em análise de aglomerados
}

\author{
Diego Mondadori Rodrigues UNISINOS \\ Miguel Afonso Sellitto UNISINOS
}

\section{RESUMO}

O objetivo deste artigo foi explorar uma técnica de análise multivariada de dados, a análise de aglomerados, proposta e aplicada para classificar os fornecedores de uma empresa da indústria automobilística segundo seus perfis de desempenho. 0 método de pesquisa foi o estudo de caso exploratório. A empresa tem concentrado seus esforços nas competências centrais do negócio e transferido atividades, principalmente a fabricação de componentes e a montagem de sub-sistemas, para fornecedores especializados. Resultou uma rede de fornecedores, organizada para abastecê-la. A empresa avalia sistematicamente seus fornecedores segundo critérios e indicadores de qualidade, de desempenho logístico e de relacionamento comercial. Os dados estão disponíveis, mas não foi desenvolvida inteligência para transformá-los em informação e auxiliar na definição de estratégias de gestão dos fornecedores. A metodologia proposta separou 107 fornecedores em até sete aglomerados com características similares de desempenho nos três critérios, permitindo a formulação de estratégias para os aglomerados. Também separou os fornecedores pelos indicadores internos aos critérios, permitindo decisões táticas e operacionais. Ao fim, o caso e as implicações do uso da metodologia na gestão da atividade focal foram discutidos.

\section{PALAVRAS-CHAVE}

Medição multivariada de desempenho, análise multivariada de dados, análise de aglomerados, indicadores de desempenho de fornecedores, gestão de fornecedores.

\section{Suppliers performance analysis of a manufacturing firm supported by cluster analysis}

\begin{abstract}
This paper aims to explore a multivariate analysis technique, the cluster analysis, proposed and applied to classify vendors of a company from the automotive industry according to their performance profiles. The research method was the exploratory case study. The company concentrates its strengths in the core business activities, transferring to vendors tasks like fabrication of items or subsystems assembling. This practice resulted in a supply network organized to feed the focal activity. The company assesses vendors in a regular basis according to criteria and indicators of quality, logistics, and commercials. Data are available in the company's database, but there is no intelligence able to comply it and generate information to support strategy formulation in vendors managing. The proposed methodology has divided 107 vendors in up to seven clusters with similar performance characteristics under the judgements criteria. This procedure was used to formulate strategies to each specific cluster. The procedure has also divided vendors within the criteria leading to tactical and operational choices. We end the paper discussing the case and its implications on the focal activity management.
\end{abstract}

\section{KEY WORDS}

Multivariate performance measurement, multivariate data analysis, cluster analysis, suppliers performance metrics, supply management. 


\section{INTRODUÇÃO}

Desde os anos 1990, fabricantes e montadores de máquinas e equipamentos de base tecnológica vêm aumentando a integração com as empresas fornecedoras dos itens requeridos pela manufatura, formando redes de fornecimento e cadeias de suprimentos. A motivação para a integração é que fabricantes e montadores têm se concentrado mais em competências essenciais (core business) e, consequentemente, passaram a comprar uma maior parcela de seus requisitos de materiais de fornecedores especialistas (SLACK, 2002). Tal prática é chamada por Andrade e Furtado (2005) de externalização. Os autores caracterizam-na como a transferência da produção de uma manufatura a empresas externas. Neste caso, não cabe à manufatura a gestão do processo de fabricação, mas a gestão de seus resultados. A prática da externalização faz surgir redes ou cadeias de fornecedores de apoio à função compras. em particular, a formação e a manutenção de uma rede de fornecedores de qualidade são vistas como possível vantagem competitiva, o que foi reconhecido em manifestações de lideranças de empresas em congressos atuais, tais como o $4^{\circ}$ Congresso Sul-Brasileiro da Indústria Automotiva, realizado em Porto Alegre, em agosto de 2005.

A necessidade de melhorar o desempenho dos fornecedores tem tornado relevante a proposição de métodos para a sua medição (CANTO, 2004). O resultado de tais medições pode levar a empresa focal a continuar, modificar ou encerrar seu relacionamento com o fornecedor. $\mathrm{O}$ fornecedor, por sua parte, deve monitorar os mesmos fatores utilizados pelo cliente para ter certeza de que os está satisfazendo (KOTLER; ARMSTRONG, 1998). Canto (2004) argumenta que indicadores capazes de medir os aspectos importantes do fornecimento constituem uma forma coesa de avaliar o desempenho dos fornecedores ao longo do processo de compra. Kaplan e Norton (1997) argumentam que os executivos precisam de indicadores sobre vários aspectos do ambiente e do desempenho organizacional, sem os quais não teriam como manter o rumo à excelência empresarial. Sellitto (2005) aponta que as medições de desempenho comunicam os objetivos estratégicos para baixo e os resultados da sua execução para cima, englobando a totalidade do entendimento da or-
$\mathrm{Na}$ indústria automobilística, entre outras, fornecedores e compradores têm formado cadeias de suprimentos. Estas são conjuntos de empresas nas quais surgem relações de parceria e alianças sinérgicas entre os participantes. A gestão da cadeia deve garantir que os esforços individuais dos participantes, além de visar a objetivos próprios, também visem a objetivos comuns da cadeia. Para Christopher (2002), a gestão de cadeias de suprimentos (Supply Chain Management - SCM) é a extensão, para toda a cadeia externa de fornecimento, do gerenciamento logístico interno. Devido às relações interorganizacionais que surgem, esforços de redução de tempos de atravessamento, de níveis de estoques e de aumento de qualidade têm produzido ganhos de competitividade individuais, que podem resultar em ganhos compartilhados por toda a cadeia.

Ao mesmo tempo que oferecem vantagens quanto ao resultado operacional das empresas participantes, as cadeias de suprimentos ou redes de fornecedores também representam um desafio para os gestores da cadeia e da empresa focal, devido à influência que o desempenho dos fornecedores exerce sobre a competitividade desta. Na indústria automobilística, ganização acerca dos seus objetivos e das relações subjacentes de causa-efeito que foram consideradas na formulação da estratégia. Estas medições devem estar alinhadas com a visão de futuro e com as estratégias atuais, partindo da visão e descrevendo as estratégias.

A medição do desempenho de fornecedores combina múltiplosfatores parciais de desempenho, representados por variáveis múltiplas, e pode valer-se de técnicas multivariadas. A análise multivariada de dados é um conjunto de técnicas matemáticas capaz de processar dados de diversas variáveis simultaneamente, gerando informações úteis em processos decisórios (HAIR et al., 1998). Dentre as técnicas de análise multivariada disponíveis na literatura, interessa para este caso a análise de aglomerados. Esta técnica é usada em marketing (MALHOTRA, 2004), mas também pode ser aplicada em gestão de produção. A metodologia Seis Sigma, por exemplo, recomenda o uso da técnica em situações relacionadas a identificação do comportamento de variáveis de processo e de produção. Rosa, Sellitto e Mendes (2006) utilizaram a análise de aglomerados para classificação de fornecedores em uma empresa de manufatura metalomecânica que opera por encomenda. 
O objetivo deste artigo é apresentar um estudo de caso exploratório, no qual foi testada uma metodologia para análise multivariada de indicadores de desempenho de fornecedores em uma empresa da indústria automobilística. A empresa possui uma ampla base de dados de fornecedores, mas ainda não possui uma metodologia estruturada que transforme esta base em inteligência operacional, ou seja, que auxilie na tomada de decisão. A metodologia proposta e testada é baseada na técnica de análise de aglomerados, uma das traduções encontradas na literatura nacional para a expressão cluster analysis. Outras traduções encontradas são análise de agrupamentos e análise de conglomerados. A metodologia classifica e separa fornecedores, segundo os resultados de múltiplos indicadores, permitindo individualizar classes de decisão para a gestão de fornecedores. Por tratar com objeto único, em fase inicial, a metodologia adequada ao caso foi o estudo de caso exploratório. Após a introdução, seguem: revisão da literatura, apresentação da metodologia proposta, teste e discussão da mesma e considerações finais.

Métodos de análise semelhantes ao apresentado neste artigo, usando análise de aglomerados, surgem na literatura. Dentre outros, alguns podem ser citados. Harland et al. (2001) propuseram um modo de classificar redes de suprimentos. Lassar e Kerr (2006) classificaram canais de marketing. Weber, Current e Benton (1991) e Boer, Labro e Morlacchi (2001) revisaram métodos de seleção de fornecedores. Meade e Sarkis (1998) e Frohlich e Westbrook (2001) fazem considerações estratégicas em gerenciamento de cadeias de suprimentos. Narasimhan, Talluri e Mendez (2001) e Sarkis e Talluri (2002) avaliaram fornecedores separando-os em aglomerados. Rosa, Sellitto e Mendes (2006) separaram fornecedores em aglomerados pelo método $k$-means. Kuei, Madu e Lin (2001) testaram e classificaram a relação entre o desempenho na cadeia de suprimentos e o desempenho empresarial.

\section{GESTÃO DE FORNECEDORES}

Slack (2002) argumenta que a gestão de fornecedores tem crescido em importância nas organizações de manufatura, levando-as a desenvolver métodos para este processo. Arnold (1999) e Slack (2002) apresentam sequências de atividades ligeiramente diferentes para o processo de gestão de fornecedores, mas que podem ser sumarizadas em: (i) determinação das especificações de compra; (ii) avaliação e seleção de fornecedores; (iii) desenvolvimento e aprimoramento de fornecedores; (iv) negociação de termos e condi- ções de compra; (v) emissão e administração de pedidos; (vi) criação e aplicação de classificações dos fornecedores; e (vii) certificação de fornecedores.

A avaliação de fornecedores identifica as empresas aptas a integrar a cadeia de suprimentos (fornecedores potenciais) da empresa. Esta avaliação se dá em: (i) qualificação do projeto por avaliação de amostras; e (ii) qualificação do seu processo de fabricação por avaliação na planta do fornecedor (auditorias). Se o fornecedor é aprovado na etapa de avaliação, segue no processo de seleção, definindo-se a fonte de fornecimento. Esta etapa envolve fatores, tais como: capacidade produtiva, competência técnica, natureza estratégica do produto fornecido, habilidade de satisfazer as programações de entrega, serviço de pós-venda, localização geográfica e preço (ARNOLD, 1999; PIRES, 2004).

\section{$\Delta$ necessidade de melhorar o desempenho Idos fornecedores tem tornando relevante a proposição de métodos para a sua medição.}

O desenvolvimento de fornecedores se dá por atividades, tais como: avaliações iniciais de produto, realimentação de informações para o fornecedor e suporte técnico a ações corretivas. $\mathrm{O}$ aprimoramento envolve melhoria em produtos e processos do fornecedor e remete à gestão da qualidade. Detalhes sobre métodos de gestão da qualidade de fornecedores são encontrados em Londero, Oliveira e Chaves (2003). Para os autores, a gestão da qualidade de fornecedores é composta por ações corretivas, ações preventivas e desenvolvimento de componentes.

Ações corretivas são atividades que visam à solução imediata de problemas decorrentes de causas especiais atuando em processos, segundo metodologias de análise e solução de problemas. Fornecedores com problemas mais críticos (definidos pela gravidade do problema, tipo de componente e impacto na produção) devem participar de programas específicos de melhorias. Ações preventivas são atividades relacionadas à avaliação dos processos dos fornecedores, tais como as auditorias de processo produtivo, avaliações logísticas e treinamentos. Por fim, o desenvolvimento de componentes é formado por atividades que perpassam desde a fase de definição de conceito do produto até as fases iniciais de produção e incorporam testes, técnicas analíticas de prevenção de defeitos (FMEA, FTA, etc.) e análise de capacidade e capabilidade de processo.

Uma alternativa para a gestão de fornecedores é a certificação completa dos processos do fornecedor por parte do comprador. Neste caso, o fornecedor passa à condição de for- 
necedor de alto nível de qualidade (qualidade assegurada), sendo dispensado de inspeção no recebimento e de outras comprovações de qualidade.

Em qualquer caso, uma metodologia de classificação de fornecedores pode ajudar a definir algumas poucas políticas básicas e a selecionar a que fornecedores cada política deve ser destinada.

\section{INDICADORES DE DESEMPENHO}

Uma definição formal para indicador, segundo a perspectiva da pesquisa científica, é encontrada em Lakatos e Marconi (1991). Segundo as autoras, um indicador é um resultado mensurável (quantitativo ou qualitativo), obtido da análise de um fenômeno ou de um termo teórico a ele relacionado. O termo teórico é uma construção abstrata capaz de representar uma idéia, contendo aspectos suficientemente amplos que justificam a estruturação dos seus componentes. Exemplos de termos teóricos são as idéias contidas em expressões, tais como desempenho, competitividade e estratégia.

e resumidos quantitativamente em índices (SELLITTO; RIBEIRO, 2004).

Observa-se que indicadores são formulações que auxiliam a mensurar os conceitos, individualmente ou agrupados, conforme uma regra de importância. A medição nasce nos indicadores, passa pelas dimensões, conceitos, construtos e chega ao termo teórico, que representa a complexidade do fenômeno em avaliação (SELLITTO; RIBEIRO, 2004).

\subsection{Medição de desempenho de fornecedores}

Segundo Melnick, Stewart e Swink (2004), a medição de desempenho por indicadores conecta estratégia e realidade. Estratégia sem indicadores é inútil e indicadores sem estratégia não fazem sentido. Paladini (2002) argumenta que uma das funções de um indicador é orientar os esforços para melhoria dos processos por ele medidos. Por esta razão, é necessário um referencial para comparar com os resultados e concluir se houve ou não melhoria. Este referencial é o padrão de desempenho ou meta. O grau de atendimento aos padrões orienta a organização na tomada de decisão. Os padrões de desempenho podem ser quantitativos ou qualitativos, tangíveis ou intangíveis e devem estar conectados com a respectiva estratégia.

A medição de desempenho de fornecedores é recorrente na literatura. Diversos autores já sugeriram critérios de avaliação. Salvo diferenças, os argumentos convergem para a noção de que o desempenho dos fornecedores não pode ser avaliado individualmente. É preciso a integração dos fatores

Um termo teórico é composto por construtos e conceitos. Os construtos são definições ainda abstratas, mais próximas do real do que o termo teórico, mas mais distantes do que os conceitos. É o conceito que expressa o fenômeno real por um sistema semântico, gramatical ou simbólico, tornando-o inteligível e processável. Um conveniente conjunto de conceitos pode ser usado para representar hierarquicamente um construto dentro de um esquema teórico. Um termo teórico, para análise científi$\mathrm{ca}$, pode ser decomposto em construtos e posteriormente em conceitos, em uma estrutura hierárquica. Definido o conceito, buscam-se aspectos constituintes que sejam relevantes para a sua construção. Estes aspectos podem ser deduzidos de uma teoria pré-existente ou observados empiricamente no objeto da pesquisa, tornando-se dimensões do conceito representáveis por valores numéricos, os indicadores. Diversos indicadores podem ser combinados que afetam o desempenho dos processos de fornecimento e, conseqüentemente, da organização, resultando em uma avaliação global do fornecedor (AMERICAN SOCIETY FOR QUALITY, 1999; MARINHO; AMATO NETO, 2001; GUNASEKARAN, PATEL; TIRTIROGLU, 2001). Segundo Marinho e Amato Neto (2001), os principais benefícios de um sistema de medição de desempenho de fornecedores incluem: (i) medição objetiva, (ii) identificação de tendências de desempenho, (iii) subsídio ao processo de seleção de fornecedores, (iv) subsídio ao processo de reconhecimento do fornecedor, e (v) aprimoramento dos processos de gestão de fornecedores.

A Associação Norte-Americana para a Qualidade (American Society for Quality - ASQ) recomenda alguns indicadores de desempenho com diferentes enfoques (AMERICAN SOCIETY FOR QUALITY, 1999). Marinho e Amato Neto (2001) recomendam a avaliação de fatores 
como: entrega no prazo e quantidade correta, qualidade do produto (medida em partes por milhão - PPM) e conformidade de documentos (notas fiscais, certificados, etc.). Canto (2004) explora os modelos de medição de desempenho de fornecedores utilizados por cinco montadoras de veículos e revisa o modelo utilizado por uma multinacional de autopeças. O estudo aponta que empresas inseridas na cadeia de suprimentos da indústria automobilística avaliam seus fornecedores segundo aspectos considerados essenciais ao negócio, tais como qualidade, logística, capacitação técnica e relacionamento comercial. A importância relativa dos aspectos modifica-se conforme a estratégia da empresa.

\section{ANÁLISE DE AGLOMERADOS}

A análise de aglomerados é uma técnica multivariada em que o pesquisador busca uma estrutura que explique observações compostas por múltiplas variáveis. A análise agrupa indivíduos ou objetos, descritos por multivariáveis, tais que objetos do mesmo grupo sejam parecidos entre si e diferentes dos objetos dos outros grupos, maximizando a homogeneidade dentro do grupo e a heterogeneidade entre grupos.

A alocação de um caso a um aglomerado pode considerar a similaridade entre a correlação das variáveis ou os valores específicos. A técnica não é exata ou otimizante e há métodos de aglomeração que não são suportados por processo estatístico rigoroso. Deste modo, é importante a avaliação e validação dos resultados pelo pesquisador, segundo o interesse da pesquisa (HAIR et al., 2005).

Malhotra (2004) aponta seis etapas na análise: (i) formular o problema; (ii) escolher a medida de similaridade; (iii) escolher o processo de aglomeração; (iv) escolher o número de aglomerados; (v) aglomerar; e (vi) avaliar e interpretar a validade da aglomeração.

A medição de similaridade entre casos pode ser feita por medidas de correlação, de distância ou de associação. As primeiras usam coeficientes de correlação entre os perfis e reúnem casos com perfis semelhantes, mas que podem ter valores muito diferentes. As medidas de distância reúnem casos próximos, mesmo com perfis diferentes. Uma medida é a distância euclidiana, obtida pela soma do quadrado das diferenças entre variáveis. Outras medidas de distância são a city-block, que é a soma das diferenças absolutas das variáveis, e a distância de Malahanobis, que padroniza distâncias tomadas em diferentes unidades. As medidas de associação, por sua vez, são usadas em objetos descritos por variáveis categóricas e oferecem a medida de quanto os objetos concordam ou discordam entre si, segundo as categorias de descrição (HAIR et al., 2005). Rea e Parker (2002) citam o $V$ de Cramer como medida associativa para variáveis com múltiplas categorias e o $\Phi$ para variáveis binárias ( $V$ ou $\Phi$ igual a 1 , associação total, igual a zero associação nula).

Os processos de aglomeração podem ser hierárquicos ou não-hierárquicos. Os primeiros constroem dendogramas (tree-like), por procedimentos aglomerativos e divisivos. Nos aglomerativos, cada objeto começa isolado e vão se formando aglomerados por agrupação de objetos, até que haja um único aglomerado. Cinco algoritmos aglomerativos são mais usados: (i) ligação individual; (ii) ligação completa; (iii) ligação média; (iv) método de Ward; e (v) método do centroide. Um procedimento divisivo começa com todos os objetos agrupados em um único aglomerado. Os objetos diferentes vão saindo, até que cada objeto pertença a um único aglomerado. Em ambos os casos, escolhe-se o número de aglomerados desejados e corta-se o processo na etapa correspondente (HAIR et al., 2005).

Os processos não-hierárquicos (K-means) designam objetos a agrupamentos, segundo o número de aglomerados a serem formados. Tipicamente, escolhe-se uma semente como o centro inicial de aglomerado, e todos os objetos dentro de uma distância de referência são incluídos. Em seguida, outra semente de aglomerado é escolhida, e a designação continua até que não reste objeto isolado. Os objetos podem ser realocados se estiverem mais próximos de outro aglomerado do que do original (HAIR et al., 2005).

A Figura 1 sintetiza os tipos de métodos de análise de aglomerados.

Para a análise feita neste artigo, convém que grupos de fornecedores sejam formados a fim de que sejam tomados conjuntos de ações adequadas a cada grupo. Para tanto, utilizou-se o método não-hierárquico $K$-means. Os benefícios do método no caso são: (i) o método é capaz de auto-organizar os dados, alocando os casos de forma não-aleatória; (ii) os casos são alocados aos aglomerados segundo a similaridade das variáveis, construindo grupos com perfis similares, sem a necessidade de hierarquização; (iii) existe a possibilidade dos perfis dos aglomerados se modificarem se os dados de desempenho se modificarem; (iv) a formação dos grupos para o direcionamento das ações pela aglomeração previne viés e tendências de fundo, visto que não existem linhas de corte arbitrárias para a classificação; e (v) há agilidade na obtenção dos resultados a partir de um software estatístico. No artigo, o método classificou os fornecedores em três classes de mesma hierarquia segundo o perfil de desempenho: (i) fornecedores de alto desempenho; (ii) fornecedores de desempenho intermediário; e (iii) fornecedores de baixo desempenho. 
A classificação foi importante para que os fornecedores do primeiro grupo sejam adequadamente reconhecidos como bons fornecedores e os do terceiro grupo sejam qualificados como problemáticos ou até mesmo desqualificados pela empresa. Os fornecedores do grupo intermediário são considerados neutros e têm seu desempenho monitorado nos níveis tático e operacional.

\section{A PESQUISA}

O objetivo de pesquisa foi propor e testar uma metodologia, baseada na análise de aglomerados, para a análise de indicadores de desempenho de fornecedores de uma empresa da indústria automobilística. A empresa possui uma ampla base de dados de fornecedores, mas não possui uma metodologia estruturada que a transforme em inteligência operacional, ou seja, que sustente tomadas de decisão. Devido às características do objetivo e do objeto de estudo, o método de pesquisa foi o estudo de caso exploratório.

O método do caso examina em profundidade um fenômeno contemporâneo, não o separando do ambiente em que ocorre. O caso pode ser exploratório, levantando questões e hipóteses para futuros estudos; descritivo, buscando encontrar associações entre as variáveis de estudo; ou explanatório, descrevendo fatos e acrescentando explicações plausíveis para os mesmos (YIN, 2001). Segundo Eckstein et al. (1975, apud ROESCH, 1999), um estudo de caso pode contribuir para uma teoria de cinco modos. O primeiro modo oferece, para posteriores estudos, uma descrição profunda e específica de um objeto. O segundo modo interpreta eventuais regularidades como evidências de postulados teóricos mais gerais, ainda não verificados. $O$ terceiro modo é heurístico: uma situação é deliberadamente construída para testar uma idéia. Os quarto e quinto modos de contribuição podem ser executados em sequência ao modo heurístico. O quarto modo estabelece sondagens plausíveis de uma teoria proposta pelo modo heurístico e o quinto modo, o caso crucial, possibilita apoiar ou refutar a teoria. Nestes três últimos tipos, os objetivos são, em graduações, a exploração, a geração e o teste de teorias. Por fim, o estudo de caso é o método sugerido por Eisenhardt (1989) para a construção indutiva de teorias fundamentadas (grounded theory).

Entende-se que este seja um estudo de caso exploratório: é a aplicação inicial da idéia; e que sua contribuição seja do segundo tipo: é mais do que uma descrição de fatos, mas não chega a ser uma situação heuristicamente construída para o teste da idéia, pois trabalhou-se com dados existentes e independentes da ação de pesquisa. Caso se deseje fundamentar uma teoria sobre medição de desempenho de fornecedores, este caso pode ser usado.

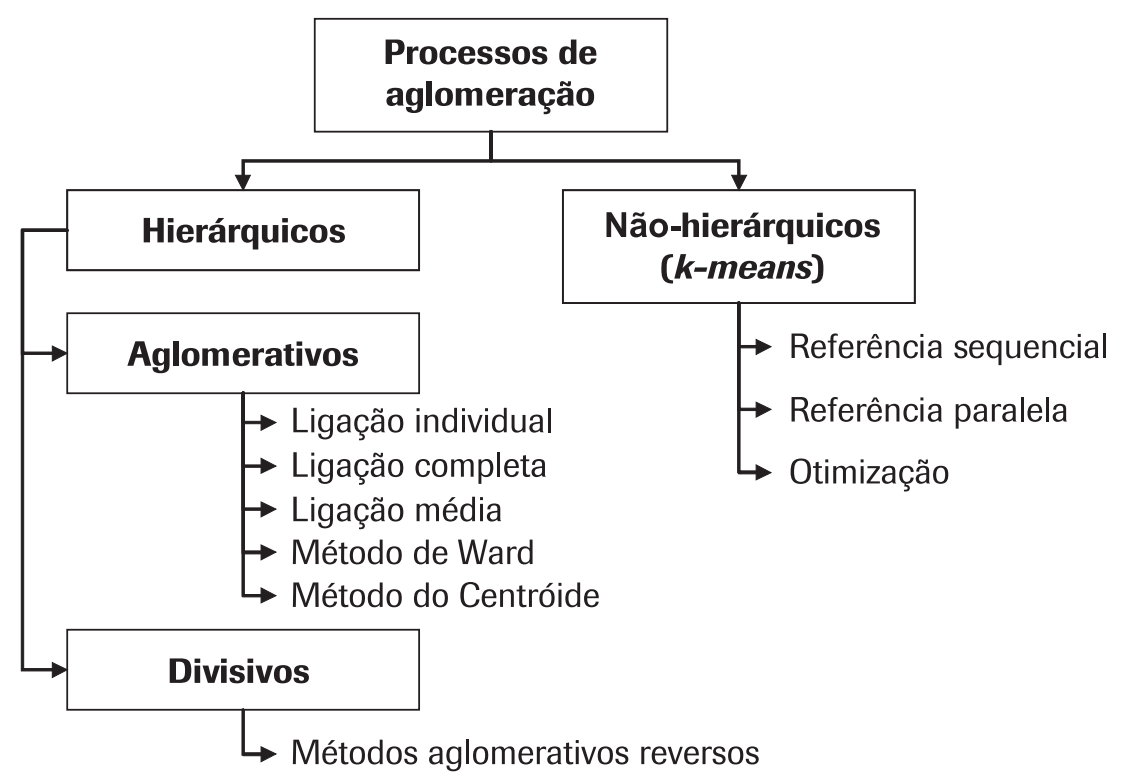

Figura 1: Tipos de métodos de análise de aglomerados.

Fonte: Hair et al., 1998 
A empresa que sediou o caso foi a MWM International Motores, nascida da aquisição da MWM Motores pelo International Engine Group, líder mundial na fabricação de motores diesel até $300 \mathrm{cv}$. A empresa produz motores para picapes, caminhões e máquinas agrícolas e geradores, contando com cerca de duzentos fornecedores. Dentre eles, estão fornecedores de autopeças e componentes de motores, tais como blocos e cabeçotes, juntas, injetados plásticos, bombas de combustível e bombas de óleo, virabrequins, turbocompressores, sistemas de injeção, alternadores, motores de partida e filtros, pistões, anéis, bielas e bronzinas, sistemas de acionamento de válvula e sincronismo, bombas hidráulicas e de vácuo e parafusos. Dentre os clientes, estão fabricantes, tais como: Ford, General Motors, Volkswagen, Volvo, AGCO, Troller e Stemac. A empresa externaliza mais de $95 \%$ dos itens requeridos pela manufatura e aplica práticas logísticas e gestão de qualidade para melhorar a integração com a base de fornecedores e obter mais agilidade e confiabilidade da cadeia. A empresa opera duas plantas no Brasil, em Canoas (RS) e em São Paulo (SP). Este estudo limita-se à planta de Canoas.

Nas informações de base, relata-se o processo de compra, identificam-se os agentes envolvidos, as interfaces e o método usado para a medição do desempenho de fornecedores. Foram consultados manuais de procedimentos internos e foram feitas entrevistas em profundidade com diversos gestores e especialistas da empresa focal. Após, apresentamse as análises global, agregadas por categoria e individuais. A análise global separou fornecedores pelo índice global, chegando a propostas de decisões de tipo estratégico, que interessam à função suprimentos. As análises agregadas separaram fornecedores com base em índices específicos de qualidade, logística e compras, chegando a propostas de decisões para as funções específicas. Por fim, as análises individuais separaram fornecedores pelos indicadores de qualidade e logística, gerando decisões locais, válidas para atividades e processos locais.

Foi usado o método $K$-means, operado pelo software Minitab 14.

\subsection{Informações de base}

O modelo de gestão é orientado por processos, segundo a ISO/TS 16949:2002, e alinha aos macroprocessos da empresa os esforços dos seguintes departamentos: Engenharia de Planejamento e Desenvolvimento de Produto, Qualidade, Compras, Manufatura, Vendas e Marketing, Peças de Reposição, Controladoria e Recursos Humanos.
As relações com fornecedores ocorrem pela área de Compras Produtivas, ligada ao departamento de Compras; pela Engenharia da Qualidade de Fornecedores (Suppliers Quality Engineering - SQE), ligada ao departamento da Qualidade, e pela área de Logística, ligada ao departamento de Manufatura.

A área de compras identifica fornecedores potenciais, inclui na cadeia e estabelece relações comerciais. A área de $S Q E$ os avalia, aprova ou não a inclusão na cadeia e monitora a qualidade dos recebimentos. A área de Logística administra o processo de suprimentos e gerencia para que o fornecimento ocorra nos prazos e quantidades requeridas. As três áreas são responsáveis por formar e manter a base de fornecedores. Para tanto, um requisito de gestão é a medição e o controle do desempenho dos fornecedores.

\section{m dos objetivos da medição de desempenho é ser o elo de realimentação de ações de} controle, cujas atividades ocorrem em ciclos contínuos de realimentação cibernética.

Para a medição, identificam-se os aspectos do processo de compra que são influenciados pelo desempenho dos fornecedores e as variáveis de campo que possam apreende-los, os indicadores. Também se definem padrões de desempenho esperados. Os indicadores são organizados em um sistema integrado, o Sistema de Avaliação Global do Fornecedor (Global Supplier Rating System - GSRS).

A estrutura do GSRS desdobra as medições em hierarquia: índice global, índices das categorias e indicadores individuais. O GSRS mede o termo teórico desempenho global do fornecedor, composto por três construtos: desempenho em qualidade, desempenho em logística e desempenho comercial, que se desdobram em conceitos apreendidos por onze indicadores. Os resultados dos indicadores são convertidos em notas entre zero e dez pontos. Cada categoria forma um índice e gera uma nota, que é a média ponderada dos indicadores que a compõem. As ponderações foram definidas no planejamento estratégico da empresa.

Conhecida a medição, os níveis da organização podem tomar ações de controle. Os gestores das áreas funcionais (qualidade, logística e compras) podem utilizar os índices das categorias para controle tático e indicadores individuais para controle operacional.

O Quadro 1 apresenta as ponderações e descreve os conceitos e indicadores. A Figura 2 integra os conceitos e os relaciona com os níveis de objetivos. 
Quadro 1: Estrutura de medição do desempenho de fornecedores - GSRS.

\begin{tabular}{|c|c|c|c|c|}
\hline \multirow[t]{2}{*}{ Construto } & \multirow{2}{*}{$\begin{array}{l}\text { Conceitos } \\
\text { e pesos }\end{array}$} & \multicolumn{3}{|c|}{ Indicadores } \\
\hline & & Denominação & Modelagem & Detalhes \\
\hline \multirow{4}{*}{ 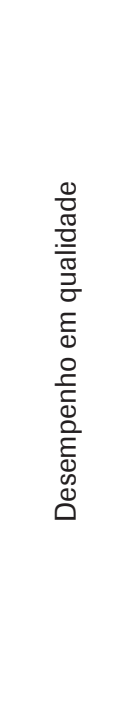 } & $\begin{array}{l}\text { Grau de } \\
\text { conformidade } \\
\text { dos processos } \\
(12 \%)\end{array}$ & $\begin{array}{l}\text { Auditoria de } \\
\text { processos }\end{array}$ & $\begin{array}{l}\text { Resultado da última } \\
\text { auditoria de processos. }\end{array}$ & $\begin{array}{l}\text { O grau de conformidade é a soma da } \\
\text { pontuação obtida em cada item de um } \\
\text { questionário estruturado para avaliação } \\
\text { do processo produtivo. }\end{array}$ \\
\hline & $\begin{array}{l}\text { Nível de rejeição } \\
\text { mensal }(9 \%)\end{array}$ & $\begin{array}{l}\text { Desempenho } \\
\text { de qualidade }\end{array}$ & $\begin{array}{l}\text { Razão entre o índice } \\
\text { PPM do mês e a meta } \\
\text { de PPM estabelecida. }\end{array}$ & $\begin{array}{l}\text { A meta de PPM é o limite de rejeições (em } \\
\text { partes por milhão) tolerado. Esta meta é } \\
\text { revisada anualmente. }\end{array}$ \\
\hline & $\begin{array}{l}\text { Redução do } \\
\text { nível de rejeição } \\
\text { ao longo do } \\
\text { tempo (7\%) }\end{array}$ & $\begin{array}{l}\text { Melhoria } \\
\text { contínua }\end{array}$ & $\begin{array}{l}\text { Comparação entre } \\
\text { o PPM do mês em } \\
\text { avaliação e o PPM } \\
\text { acumulado dos últimos } \\
\text { doze meses. }\end{array}$ & $\begin{array}{l}\text { O fornecedor recebe nota dez se apresentar } \\
\text { redução de PPM em } 50 \% \text { ou mais em relação } \\
\text { ao PPM acumulado. Se a redução for inferior a } \\
50 \% \text { a nota é proporcional. }\end{array}$ \\
\hline & $\begin{array}{l}\text { Atendimento } \\
\text { aos prazos dos } \\
\text { relatórios de } \\
\text { ação corretiva } \\
\text { (RAC) }(6 \%)\end{array}$ & $\begin{array}{l}\text { Resposta } \\
\text { às ações } \\
\text { corretivas }\end{array}$ & $\begin{array}{l}\text { Razão entre as etapas } \\
\text { de RACs atendidas no } \\
\text { prazo e o número de } \\
\text { etapas com respostas } \\
\text { previstas. }\end{array}$ & $\begin{array}{l}\text { Um RAC estabelece uma metodologia de } \\
\text { solução e é emitido quando um problema } \\
\text { de qualidade é detectado. Cada etapa da } \\
\text { metodologia tem um prazo a ser cumprido } \\
\text { pelo fornecedor. }\end{array}$ \\
\hline \multirow{4}{*}{ 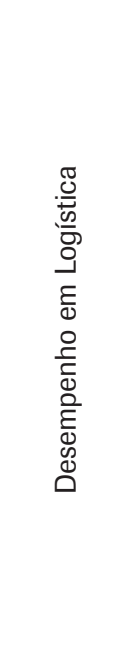 } & $\begin{array}{l}\text { Entrega nos } \\
\text { prazos (9\%) }\end{array}$ & $\begin{array}{l}\text { Performance } \\
\text { de entrega }\end{array}$ & $\begin{array}{l}\text { Razão entre o número } \\
\text { de pedidos entregues } \\
\text { no prazo e o total de } \\
\text { pedidos colocados. }\end{array}$ & $\begin{array}{l}\text { Os prazos possuem folgas (janelas de entrega) } \\
\text { segundo a classificação } A B C \text { (classificação pelo } \\
\text { preço do produto). }\end{array}$ \\
\hline & $\begin{array}{l}\text { Aplicação } \\
\text { de práticas } \\
\text { logísticas (9\%) }\end{array}$ & $\begin{array}{l}\text { Avaliação } \\
\text { logística }\end{array}$ & $\begin{array}{l}\text { Resultado da última } \\
\text { avaliação logística. }\end{array}$ & $\begin{array}{l}\text { A avaliação é um questionário focado } \\
\text { nas práticas logísticas, infra-estrutura e } \\
\text { competências de que o fornecedor dispõe. }\end{array}$ \\
\hline & $\begin{array}{l}\text { Utilização } \\
\text { de avisos de } \\
\text { embarque } \\
\text { eletrônicos (6\%) }\end{array}$ & ASN/EDI & $\begin{array}{l}\text { Razão entre o número } \\
\text { de avisos de embarque } \\
\text { recebidos e o total de } \\
\text { pedidos colocados. }\end{array}$ & $\begin{array}{l}\text { Os avisos de embarque podem ser recebidos via } \\
\text { Internet, através do portal IESN, ou através da } \\
\text { tecnologia convencional } E D I \text {. }\end{array}$ \\
\hline & $\begin{array}{l}\text { Adequação aos } \\
\text { requisitos de } \\
\text { embalagem }(9 \%)\end{array}$ & $\begin{array}{l}\text { Adequação } \\
\text { de } \\
\text { embalagem }\end{array}$ & $\begin{array}{l}\text { Média ponderada de } \\
\text { três índices: PAK (peso } \\
\text { 4), SKU (peso 4) e BC } \\
\text { (peso 2). }\end{array}$ & $\begin{array}{l}\text { PAK: taxa de utilização de embalagem } \\
\text { retornável; SKU: taxa de atendimento às } \\
\text { quantidades padrão; e BC: utilização de } \\
\text { códigos de barra segundo o padrão } \\
\text { estabelecido (binário - zero ou dez). }\end{array}$ \\
\hline \multirow{3}{*}{ 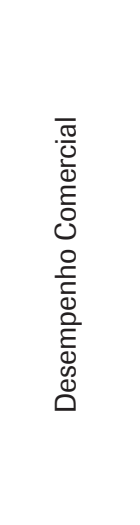 } & $\begin{array}{l}\text { Competência } \\
\text { comercial (18\%) }\end{array}$ & $\begin{array}{l}\text { Avaliação } \\
\text { comercial }\end{array}$ & $\begin{array}{l}\text { Resultado da última } \\
\text { avaliação comercial. }\end{array}$ & $\begin{array}{l}\text { A avaliação é um questionário focado em } \\
\text { aspectos como relações comerciais, negociação, } \\
\text { competitividade e proatividade do fornecedor. }\end{array}$ \\
\hline & $\begin{array}{l}\text { Certificação } \\
\text { do sistema da } \\
\text { qualidade do } \\
\text { fornecedor } \\
(12 \%)\end{array}$ & Certificação & $\begin{array}{l}\text { Pontuação relativa às } \\
\text { certificações obtidas } \\
\text { pelo fornecedor } \\
\text { conforme a certificação } \\
\text { que possui. }\end{array}$ & $\begin{array}{l}\text { Fornecedores com ISO/TS 16949:2002 e ISO } \\
\text { 14000:2000 recebem a nota dez, enquanto } \\
\text { que fornecedores que possuem apenas } \\
\text { cronograma de certificação recebem a nota } \\
\text { zero. Certificações intermediárias recebem } \\
\text { graduações proporcionais. }\end{array}$ \\
\hline & $\begin{array}{l}\text { Nível de } \\
\text { consignação dos } \\
\text { produtos (3\%) }\end{array}$ & Consignação & $\begin{array}{l}\text { Razão entre o valor } \\
\text { consignado (R\$) e o } \\
\text { saldo médio em estoque } \\
\text { no mês de avaliação. }\end{array}$ & $\begin{array}{l}\text { Consignação são lotes recebidos } \\
\text { e que só serão pagos no consumo } \\
\text { efetivo na produção. }\end{array}$ \\
\hline
\end{tabular}




\subsection{Aglomeração pelo índice global: decisões estratégicas}

O GSRS reporta mensalmente os indicadores de cento e sete fornecedores, mas ainda não há uma metodologia para interpretá-los e apoiar decisões de controle. Tal metodologia foi proposta neste estudo. Por ser exploratório, o estudo limitou-se a três meses consecutivos, de agosto a outubro de 2005, o que totalizou trezentos e vinte e uma variáveis, pois a cada objeto foram associados três conjuntos de indicadores. Para separar os fornecedores em grupos, tentaram-se quatro, cinco, seis e sete aglomerados. Ao fim, optou-se por seis aglomerados. Devido à inexatidão da técnica, alguma subjetividade pode ser admitida na validação do resultado e na escolha do número de aglomerados.

Para explicar a operação, apresentam-se, na Tabela 1, os valores individuais e as médias mensais do índice global para os sete fornecedores do aglomerado 1 , o de mais alto desempenho. Os dados são repetidos na Tabela 2, junto com os dados dos demais aglomerados. Outros vinte e cinco fornecedores foram incluídos no aglomerado $2 \mathrm{e}$ assim por diante. A tabela também contém a média dos desempenhos médios mensais, o desvio-padrão destas médias e uma classificação do desempenho dos aglomerados. Para o cálculo dos desvios-padrão, foram considerados apenas os valores das médias mensais.

Os fornecedores dos aglomerados 1 e 3 apresentam notas médias acima de 7,5 e baixa variabilidade, podendo ser considerados como de alto desempenho. Sugere-se que passem a integrar um programa específico de reconhecimento, envolvendo premiações e estímulos à manutenção da qualidade, que podem incluir aumento de valor em fornecimentos. Os fornecedores dos aglomerados 2 e 5 apresentam notas intermediárias e baixa variabilidade. Sugere-se que os fornecedores destes aglomerados iniciem estudos para melhoria de processo, com avanço monitorado. $\mathrm{O}$ aglomerado 4 apresenta alta variabilidade, portanto, além de melhorar processo, deve procurar causas especiais. $\mathrm{O}$ aglomerado 6 apresenta situação mais grave, sugerindose um programa de intervenção específica de melhorias, sem o que, poderá haver desqualificação temporária ou definitiva destes fornecedores.

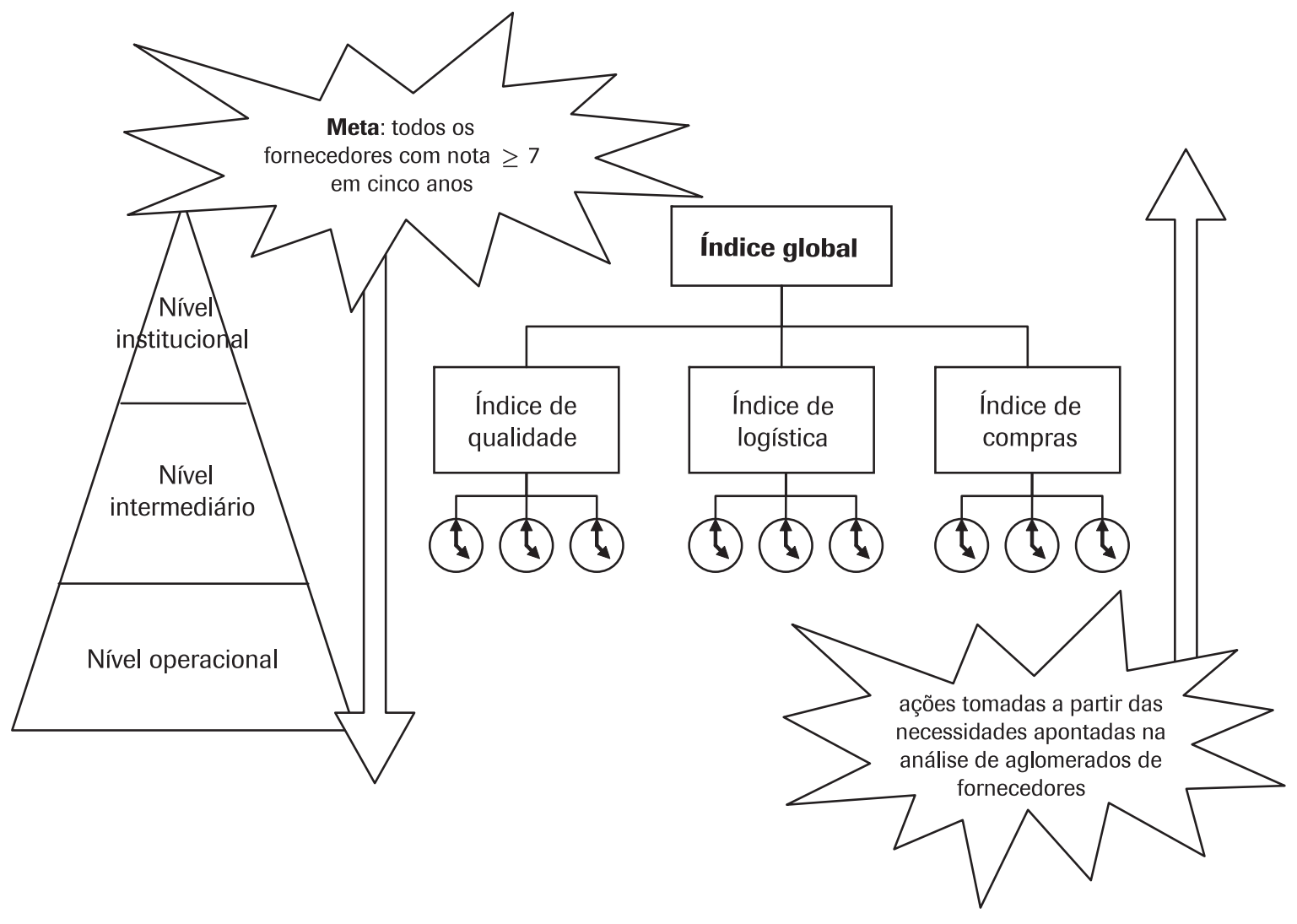

Figura 2: Relação de medições e objetivos estratégicos da empresa.

Fonte: empresa estudada 


\subsection{Aglomeração por índices de categoria: decisões táticas}

As próximas aglomerações foram feitas pelos índices de categoria. Inicia-se pela categoria qualidade (Tabela 3).

Tabela 1: Desempenhos globais dos sete fornecedores do aglomerado 1.

\begin{tabular}{cccc}
\hline Fornecedor & Mês 1 & Mês 2 & Mês 3 \\
\hline 1 & 8,8 & 8,8 & 7,1 \\
2 & 8,1 & 8,5 & 8,4 \\
3 & 8,8 & 8,8 & 9,1 \\
4 & 8,9 & 8,7 & 8,0 \\
5 & 9,4 & 9,3 & 7,5 \\
6 & 9,7 & 9,3 & 9,3 \\
7 & 8,9 & 8,9 & 8,3 \\
Média & 8,94 & 8,90 & 8,24 \\
\hline
\end{tabular}

O aglomerado 1 tem alta média e baixa variabilidade, o que dispensa ações de controle. O aglomerado 2 apresenta fornecedores com alta média, mas alta variabilidade, o que pode indicar causas especiais. Os demais aglomerados têm médias iguais ou menores do que 5 , devendo ser alvo de programas especiais de ações corretivas, e estão sujeitos a desqualificação. Adicionalmente, os aglomerados 4 e 5 apresentam alto desviopadrão, o que pode indicar, além de desempenho médio insuficiente, causas especiais em andamento.

A segunda análise diz respeito ao desempenho logístico (Tabela 4).

Os aglomerados 1, 2 e 3 têm desempenho logístico elevado e baixa variabilidade, o que dispensa ações de controle, mesmo que a mais alta variabilidade do aglomerado 2 possa indicar uma causa especial. Os demais aglomerados possuem desempenho inferior, necessitando de ações corretivas. Nesta análise, as variabilidades são menos elevadas do que as surgidas na análise de qualidade.

Tabela 2: Análise dos aglomerados pelo índice global.

\begin{tabular}{|c|c|c|c|c|c|c|}
\hline & \multicolumn{6}{|c|}{ Aglomerado } \\
\hline & 1 & 2 & 3 & 4 & 5 & 6 \\
\hline número de casos & 7 & 25 & 24 & 7 & 23 & 21 \\
\hline Média do mês 1 & 8,94 & 6,96 & 7,69 & 7,31 & 6,13 & 5,10 \\
\hline Média do mês 2 & 8,90 & 7,32 & 7,74 & 5,92 & 6,17 & 4,71 \\
\hline Média do mês 3 & 8,24 & 6,58 & 7,59 & 4,61 & 5,94 & 4,70 \\
\hline$\mu$ das médias & 8,7 & 7,0 & 7,7 & 6,0 & 6,1 & 4,8 \\
\hline$\sigma$ das médias & 0,39 & 0,37 & 0,07 & 1,35 & 0,12 & 0,23 \\
\hline $\begin{array}{c}\text { classe de } \\
\text { desempenho e } \\
\text { tipo de decisão }\end{array}$ & $\begin{array}{l}\text { programa de } \\
\text { reconhecimento } \\
\text { e premiação }\end{array}$ & $\begin{array}{c}\text { melhoria de } \\
\text { processo e } \\
\text { monitoração de } \\
\text { avanço }\end{array}$ & $\begin{array}{l}\text { programa de } \\
\text { reconhecimento } \\
\text { e premiação }\end{array}$ & $\begin{array}{c}\text { melhoria de } \\
\text { processo e } \\
\text { causas especiais }\end{array}$ & $\begin{array}{c}\text { melhoria de } \\
\text { processo e } \\
\text { monitoração de } \\
\text { avanço }\end{array}$ & $\begin{array}{c}\text { programa de } \\
\text { melhorias e } \\
\text { controle de } \\
\text { desempenho }\end{array}$ \\
\hline
\end{tabular}

Tabela 3: Análise de aglomerados pelo índice de qualidade.

\begin{tabular}{|c|c|c|c|c|c|c|}
\hline & \multicolumn{6}{|c|}{ Aglomerado } \\
\hline & 1 & 2 & 3 & 4 & 5 & 6 \\
\hline número de casos & 73 & 13 & 8 & 7 & 2 & 4 \\
\hline Média do mês 1 & 9,40 & 9,43 & 3,62 & 9,34 & 0,00 & 2,15 \\
\hline Média do mês 2 & 9,02 & 9,31 & 6,30 & 2,41 & 0,00 & 1,70 \\
\hline Média do mês 3 & 9,50 & 2,40 & 4,95 & 1,72 & 6,85 & 0,15 \\
\hline$\mu$ das médias & 9,3 & 7,1 & 5,0 & 4,5 & 2,3 & 1,3 \\
\hline$\sigma$ das médias & 0,25 & 4,03 & 1,34 & 4,21 & 3,95 & 1,05 \\
\hline $\begin{array}{l}\text { classe de desempenho e } \\
\text { tipo de decisão }\end{array}$ & $\begin{array}{l}\text { sem ações de } \\
\text { controle }\end{array}$ & $\begin{array}{c}\text { buscar causas } \\
\text { especiais }\end{array}$ & $\begin{array}{c}\text { programa de } \\
\text { ações corretivas }\end{array}$ & $\begin{array}{l}\text { programa } \\
\text { de ações } \\
\text { corretivas }\end{array}$ & $\begin{array}{l}\text { programa } \\
\text { de ações } \\
\text { corretivas }\end{array}$ & $\begin{array}{c}\text { programa de } \\
\text { ações corretivas }\end{array}$ \\
\hline
\end{tabular}


A terceira análise diz respeito ao desempenho em compras (Tabela 5).

Os dois fornecedores do aglomerado 1 se destacam, com médias superiores a 9,0 e variabilidade nula. Os aglomerados 2 e 3 apresentam fornecedores com notas médias iguais ou superiores a 7,0 e variabilidades baixas, não se recomendando ações neste nível. Os fornecedores dos demais aglomerados apresentam desempenho intermediário e devem ser alvo de programas de ações corretivas, com monitoração de avanço das ações, não apenas do desempenho final.

\subsection{Aglomeração por indicadores: decisões operacionais}

A última análise foi feita dentro das categorias qualidade e logística. Recordando a inexatidão da técnica, desta vez optou-se por quatro aglomerados. A categoria comercial não participou desta parte da análise, porque seus indicadores não são mensurados todos os meses, sendo pouco úteis em decisões locais, de curto prazo. Inicia-se pela categoria quali- dade (Tabela 6). Como cerca de 75\% dos fornecedores ainda não foram auditados, este indicador ficou de fora.

O aglomerado 2 reúne fornecedores com bom desempenho em qualidade, requerendo apenas programa de ações preventivas, que iniciam com a auditoria de processos. $\mathrm{O}$ aglomerado 1 reúne fornecedores que apresentaram problemas de qualidade, mas que ou responderam satisfatoriamente às ações corretivas ou não receberam relatórios de ação corretiva. Em ambos os casos, atribuiu-se nota elevada ao indicador. Recomenda-se apenas a monitoração da eficácia das ações já adotadas. Caso estas não sejam eficazes, novas decisões deverão ser tomadas, desta vez mais rigorosas. $\mathrm{O}$ aglomerado 3 reúne fornecedores com bom desempenho de qualidade, mas que não responderam às ações referentes a problemas anteriores. Propõe-se identificar a causa do não atendimento. Eventualmente, a falha pode decorrer da falta de treinamento quanto ao preenchimento do relatório, pois este é feito no portal de fornecedores. O aglomerado 4 , por fim, reúne fornecedores de baixo desempenho. Caso

Tabela 4: Análise de aglomerados pelo índice de logística.

\begin{tabular}{|c|c|c|c|c|c|c|}
\hline & \multicolumn{6}{|c|}{ Aglomerado } \\
\hline & 1 & 2 & 3 & 4 & 5 & 6 \\
\hline número de casos & 3 & 7 & 9 & 29 & 27 & 32 \\
\hline Média do mês 1 & 9,67 & 9,20 & 8,46 & 5,93 & 3,55 & 7,31 \\
\hline Média do mês 2 & 9,67 & 9,15 & 8,15 & 6,08 & 3,95 & 7,74 \\
\hline Média do mês 3 & 9,57 & 7,72 & 7,72 & 4,95 & 3,33 & 6,91 \\
\hline$\mu$ das médias & 9,6 & 8,7 & 8,1 & 5,7 & 3,6 & 7,3 \\
\hline$\sigma$ das médias & 0,06 & 0,84 & 0,37 & 0,61 & 0,31 & 0,41 \\
\hline $\begin{array}{l}\text { classe de desempenho e } \\
\text { tipo de decisão }\end{array}$ & $\begin{array}{l}\text { sem ações de } \\
\text { controle }\end{array}$ & $\begin{array}{l}\text { sem ações de } \\
\text { controle }\end{array}$ & $\begin{array}{l}\text { sem ações de } \\
\text { controle }\end{array}$ & $\begin{array}{c}\text { programa de } \\
\text { ações corretivas }\end{array}$ & $\begin{array}{c}\text { programa de } \\
\text { ações corretivas }\end{array}$ & $\begin{array}{c}\text { programa de } \\
\text { ações corretivas }\end{array}$ \\
\hline
\end{tabular}

Tabela 5: Análise de aglomerados pelo índice de compras.

\begin{tabular}{|c|c|c|c|c|c|c|}
\hline & \multicolumn{6}{|c|}{ Aglomerado } \\
\hline & 1 & 2 & 3 & 4 & 5 & 6 \\
\hline Número de casos & 2 & 14 & 30 & 16 & 32 & 13 \\
\hline Mês 1 & 9,40 & 7,69 & 6,72 & 5,50 & 6,09 & 2,83 \\
\hline Mês 2 & 9,40 & 7,66 & 7,14 & 4,98 & 6,21 & 2,66 \\
\hline Mês 3 & 9,40 & 7,75 & 7,18 & 4,88 & 6,23 & 2,66 \\
\hline Média & 9,4 & 7,7 & 7,0 & 5,1 & 6,2 & 2,7 \\
\hline Desvio-padrão & 0,00 & 0,05 & 0,25 & 0,33 & 0,07 & 0,10 \\
\hline $\begin{array}{l}\text { classe de desempenho } \\
\text { e tipo de decisão }\end{array}$ & $\begin{array}{l}\text { sem ações de } \\
\text { controle }\end{array}$ & $\begin{array}{l}\text { sem ações de } \\
\text { controle }\end{array}$ & $\begin{array}{l}\text { sem ações de } \\
\text { controle }\end{array}$ & $\begin{array}{c}\text { programa de } \\
\text { ações corretivas }\end{array}$ & $\begin{array}{c}\text { programa de } \\
\text { ações corretivas }\end{array}$ & $\begin{array}{c}\text { programa de } \\
\text { ações corretivas }\end{array}$ \\
\hline
\end{tabular}


se tratem de problemas isolados, estes devem ser tratados pela metodologia de ações corretivas em vigor. Para falhas reincidentes, propõe-se que o fornecedor seja acompanhado, em planta, por engenheiro de $S Q E$, para identificação dos problemas e posterior definição de plano de ação corretiva.

Passa-se à categoria logística (tabela 7). O indicador de avaliação logística ficou fora, pois não é mensurado todos os meses.

O aglomerado 1 reúne fornecedores com desempenho logístico satisfatório (média alta, variabilidade baixa), cabendo apenas trabalho preventivo, pelas avaliações logísticas. O aglomerado 2 reúne fornecedores cujo principal problema reside na adequação de embalagens e performance de entrega. Neste caso, propõe-se que os casos sejam detalhados e tratados individualmente pela metodologia adotada de análise e solução de problemas. $\mathrm{O}$ aglomerado 3 reúne fornecedores com boa performance de entrega, mas baixo desempenho em embalagem e EDI. A causa pode estar relacionada a questões comerciais, tais como cláusulas de contrato ou dificuldades técnicas ou financeiras do fornecedor. Há má resposta a ações que já foram tomadas. Em qualquer caso, estas questões devem ser avaliadas com relação a sua incidência e, no caso de problemas sistêmicos, um programa de melhoria pode ser empregado. O aglomerado 4 reúne fornecedores com baixo desempenho. Propõe-se que os casos sejam avaliados e identificados quanto a incidência dos problemas. Os casos sistêmicos devem ser tratados através de programas de melhoria específicos. Propõe-se que o indicador de consignação seja analisado a partir de um planejamento da área de compras, em que os fornecedores sejam incentivados a aderir a esta prática. A complementação poderia ser a formalização da obrigatoriedade de consignação. Outras ações não são recomendadas devido ao baixo impacto que este indicador tem no índice global (3\%).

\subsection{Dinâmica do controle para gestão apoiada em indicadores}

Um dos objetivos da medição de desempenho é ser o elo de realimentação de ações de controle, cujas atividades ocorrem em ciclos contínuos de realimentação cibernética. As infor-

Tabela 6: Análise de aglomerados por indicadores da qualidade.

\begin{tabular}{|c|c|c|c|c|}
\hline & \multicolumn{4}{|c|}{ Aglomerado } \\
\hline & 1 & 2 & 3 & 4 \\
\hline Número de casos & 17 & 64 & 12 & 13 \\
\hline Resposta às ações corretivas & 9,8 & 9,8 & 0,0 & 1,5 \\
\hline Melhoria contínua & 1,7 & 10 & 10 & 0,0 \\
\hline Desempenho de qualidade & 1,0 & 9,8 & 8,7 & 0,5 \\
\hline Média & 4,2 & 9,9 & 6,3 & 0,7 \\
\hline Desvio-padrão & 4,9 & 0,1 & 5,5 & 0,8 \\
\hline classe de desempenho e tipo de decisão & $\begin{array}{l}\text { monitoração das } \\
\text { ações já tomadas }\end{array}$ & $\begin{array}{c}\text { programa de ações } \\
\text { preventivas }\end{array}$ & $\begin{array}{c}\text { má resposta às } \\
\text { ações já tomadas }\end{array}$ & $\begin{array}{l}\text { metodologia de } \\
\text { ações corretivas }\end{array}$ \\
\hline
\end{tabular}

Tabela 7: Análise de aglomerados por indicadores de logística.

\begin{tabular}{|c|c|c|c|c|}
\hline & \multicolumn{4}{|c|}{ Aglomerado } \\
\hline & 1 & 2 & 3 & 4 \\
\hline Número de casos & 37 & 17 & 28 & 24 \\
\hline ASN/EDI & 7,8 & 8,6 & 0,7 & 0,6 \\
\hline Adequação de embalagem & 7,0 & 3,8 & 5,2 & 5,4 \\
\hline Performance de entrega & 8,4 & 3,2 & 9,4 & 2,2 \\
\hline Média & 7,7 & 5,2 & 5,1 & 2,8 \\
\hline Desvio-padrão & 0,7 & 3,0 & 4,3 & 2,5 \\
\hline classe de desempenho e tipo de decisão & $\begin{array}{l}\text { programa de ações } \\
\text { preventivas }\end{array}$ & $\begin{array}{l}\text { metodologia de } \\
\text { ações corretivas }\end{array}$ & $\begin{array}{l}\text { má resposta às } \\
\text { ações já tomadas }\end{array}$ & $\begin{array}{l}\text { metodologia de } \\
\text { ações corretivas }\end{array}$ \\
\hline
\end{tabular}


mações comunicam objetivos para baixo e retornam medições para cima. Nos ciclos de controle, estabelecem-se ações, cuja implementação pode ser conduzida por diferentes níveis. Planos de ações definidos para um grupo de fornecedores no nível estratégico podem ser comunicados ao nível tático como objetivos. Resultados de ações conduzidas no nível operacional podem retornar ao nível tático e deste ao nível estratégico, realimentando o processo. Em todos os casos, os indicadores são os meios pelos quais esta dinâmica se dá.

Encerra-se este estudo propondo uma hierarquização, tal que, em cada nível, exista um ciclo de controle que resulte em ações, coerentes com o nível do ciclo. Cada nível também trata das questões que sobem (no caso do nível estratégico), sobem e descem (no caso do nível tático) ou descem (no caso do nível operacional). Os dados de entrada das ações são os resultados das análises do desempenho do nível e as informações vindas de outros níveis.

Os ciclos giram com velocidades diferentes em cada nível de controle. A proposta é que o ciclo estratégico aconteça a cada três meses, o ciclo tático a cada dois meses e o ciclo operacional todo mês, o que assegura que problemas em um nível superior tenham sido tratados primeiramente nos níveis inferiores. A cada ciclo de controle, novas aglomerações podem ser geradas, orientando as ações para a melhoria contínua, pois, pelo perfil de desempenho, serão direcionadas ações adequadas a cada grupo. O ciclo de comunicação e controle promove a dinâmica e assegura a sintonia entre níveis quanto às ações de controle.

O esquema da dinâmica proposta, e que foi usado de modo exploratório neste trabalho, está exposto na Figura 3.

\section{CONSIDERAÇÕES FINAIS}

O propósito deste artigo foi propor e testar, em uma empresa da indústria automobilística, uma metodologia de análise de desempenho de fornecedores, apoiada na técnica de análise de aglomerados. Tais dados encontravam-se disponíveis para análise, porém, a empresa ainda não definiu um método para o desdobramento do desempenho medido

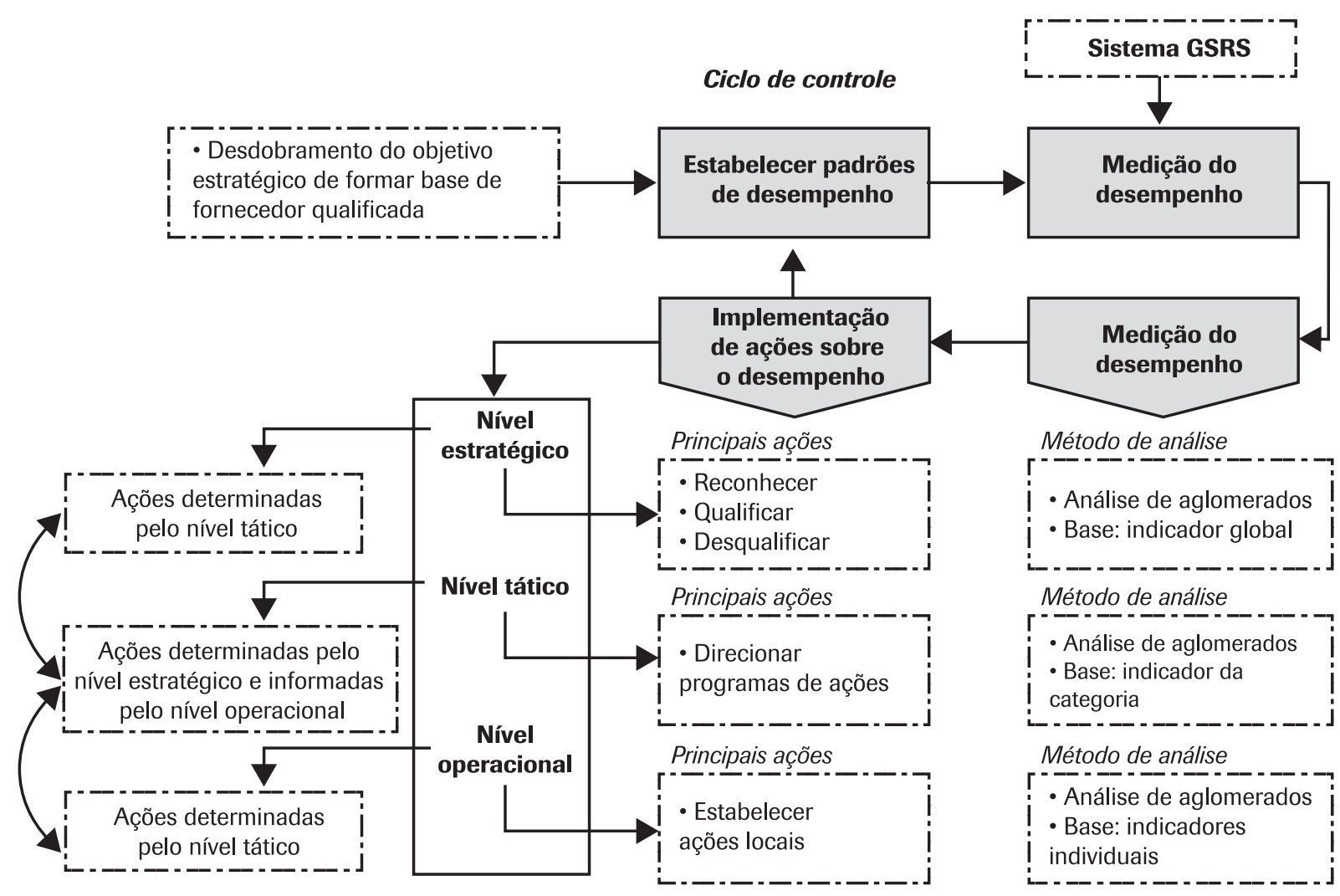

Níveis de controle

Figura 3: Dinâmica de ações de controle realimentadas por medições. 
em ações de controle, o que ofereceu a possibilidade de um estudo de caso.

Antes da metodologia, foram revisados conceitos pertinentes ao caso, a fim de estabelecer um referencial teórico para o trabalho. Após, descreveu-se a empresa e seu modelo de gestão de fornecedores. A seguir, apresentou-se e testou-se a metodologia, chegando-se a aglomerados de desempenho de fornecedores, em três níveis, o que permitiu especificar uma tipologia de decisões adequadas aos grupos formados pela aglomeração.

A tipologia de decisões explora três eixos principais: seleção de fornecedores, monitoramento do desempenho de fornecedores selecionados e programa de premiação a fornecedores monitorados de alto desempenho. A sistemática proposta para a avaliação de fornecedores, baseada em indicadores, resulta da análise crítica do caso e representa um avanço em relação aos critérios atualmente em uso pela empresa focal. O monitoramento de fornecedores é baseado no desdobramento dos padrões de desempenho e no ciclo de controle, pela estrutura hierárquica do GSRS. O objetivo do desdobramento dos padrões de desempenho é proporcionar conectividade entre os níveis, buscando o alinhamento com os objetivos estratégicos para qualidade de fornecedores. Para os fornecedores que persistentemente apresentem desempenho alto, a proposição é que participem de um programa de premiação e reconhecimento, com pontos que podem envolver aumento de volume de negócios ou dispensa de etapas custosas, tais como inspeções.

A análise de aglomerados formou grupos de fornecedores com características similares dentro dos grupos e distintas entre os grupos, o que permitiu que poucas políticas básicas fossem especificadas para os cento e sete fornecedores estudados. Com base na análise, apontam-se possíveis ações de controle a serem implementadas, que levam em conta a coerência com as práticas empregadas na indústria automobilística levantadas no referencial teórico e no estudo de caso. Ao fim, formalizou-se a utilização de ciclos de controle nos níveis da estratégia, sintetizando a proposição na Figura 3.

Novas questões de pesquisa emergiram ao longo do trabalho, remetendo a linhas alternativas de continuidade.

Uma alternativa é a gestão de desempenho de forma sinótica, por visualização. Gráficos de área capazes de representar o perfil do desempenho de todos os fornecedores poderiam ser úteis ao monitoramento. Outras técnicas multivariadas, tais como a regressão múltipla, ou modelagens estatísticas, capazes de medir centralização e dispersão de dados, tais como os gráficos de caixa (box-plot), poderiam ser utilizadas. Neste caso, há a necessidade de conectar o esforço de pesquisa ao campo de conhecimento dos sistemas de informação. Outra alternativa de pesquisa poderia avaliar a modelagem utilizada no sistema GSRS e validar sua aderência aos processos atuais. Aspectos do processo de aquisição ainda não contemplados no sistema, tais como aqueles relacionados à etapa de desenvolvimento, poderiam ser avaliados. Outros indicadores poderiam ser criados ou modificados, visto que os critérios de competitividade estão em constante mutação. A importância relativa (distribuição dos pesos) entre os indicadores também poderia ser analisada, propondo-se, para tanto, o uso de métodos multicriteriais para sua definição.

\section{Artigo recebido em 04/2007 Aprovado para publicação em 15/12/2008}

\section{REFERÊNCIAS}

AMERICAN SOCIETY FOR QUALITY. The certified quality handbook. Milwaukee: ASQ Quality Press, 1999.

ANDRADE, C.; FURTADO, J. Discutindo processos de outsourcing da manufatura: uma análise a partir de elementos das indústrias eletrônica, farmacêutica e automobilística. Anais do XXV ENEGEP, Porto Alegre, 2005.

ARNOLD, J. Administração de materiais: uma introdução. São Paulo: Atlas, 1999.
BOER, L.; LABRO, E.; MORLACCHI, P. A review of methods supporting supplier selection. European Journal of Purchasing \& Supply Management, v. 7, n. 2, p. 75-89, 2001.

CANTO, R. Proposta de revisão do modelo de avaliação do desempenho dos fornecedores da GKN do Brasil Ltda. 2004. Dissertação (Mestrado em Engenharia de Produção) Escola de Engenharia, Universidade Federal do Rio Grande do Sul, Porto Alegre, 2004.

CHIAVENATO, I. Administração nos novos tempos. 2. ed. São Paulo: Makron Books, 1999.
CHRISTOPHER, M. Logística e gerenciamento da cadeia de suprimentos: estratégias para redução de custos e melhoria dos serviços. São Paulo: Pioneira, 2002.

EISENHARDT, K. Building theories from case study research. Academy of Management Review, v. 14, n. 4, p. 532-550, 1989.

GUNASEKARAN, A.; PATEL, C.; TIRTIROGLU, E. Performance measures and metrics in a supply chain environment. International Journal of Operations \& Production Management, v. 21, n. 1 e 2, p. 71-87, 2001. 
FROHLICH, M; WESTBROOK, R. Arcs of integration: an international study of supply chain strategies. Journal of Operations Management. v. 19, n. 2, p.185-200, 2001.

HAIR, J.; TATHAM, R.; ANDERSON, R.; BLACK W. Análise multivariada de dados. Porto Alegre: Bookman, 2005.

HARLAND, C.; LAMMING, R.; ZHENG, J.; JOHNSEN, T. A Taxonomy of Supply Networks. Journal of Supply Chain Management. v. 37, n. 4, p. 21- 27, 2001.

KAPLAN, R.; NORTON, D. A estratégia em ação: balanced scorecard. Rio Janeiro: Campus, 1997.

KOTLER, P.; ARMStRong, G. Princípios de marketing. Rio Janeiro: Prentice-Hall, 1998.

KUEI, C.; MADU, C.; LIN, C. The relationship between supply chain quality management practices and organizational performance. International Journal of Quality \& Reliability Management, v. 18, n. 8, p. 864-872, 2001.

LAKATOS, E.; MARCONI, M. Fundamentos de metodologia científica. São Paulo: Atlas, 1991.

LASSAR, W; KERR, J. Strategy and control in supplier-distributor relationships : an agency perspective. Strategic Management Journal, v. 17, n. 8, p. 613-632, 1996.

LONDERO, M.; OLIVEIRA, R.; CHAVES, F. Relações com Fornecedores: um novo enfoque, In: CONGRESSO E EXPOSIÇÃO INTERNACIONAIS DA TECNOLOGIA DA MOBILIDADE, 12., 2003, São Paulo. Anais.
São Paulo: Sociedade de Engenheiros da Mobilidade, 2003.

MALHOTRA, N. Pesquisa de marketing: uma orientação aplicada. Porto Alegre: Bookman, 2004.

MARINHO, B.; AMATO NETO, J. Gestão da cadeia de fornecedores e acordos de parcerias. In: AMATO NETO, J. (Org.) Manufatura classe mundial: conceitos, estratégias e aplicações. S. Paulo: Atlas, 2001.

MEADE, L.; SARKIS, J. Strategic analysis of logistics and supply chain management systems using the analytical network process. Transportation Research Part E: Logistics and Transportation Review, v. 34, n. 3, p. 201-215, 1998.

MELNICK, S.; STEWARD, D.; SWINK; M. Metrics and performance measurements in operations management: dealing with the metrics maze. Journal of Operations Management, v. 22, n. 3, p. 219-217, 2004.

NARASIMHAN, R.; TALLURI, S.; MENDEZ, D. Supplier Evaluation and Rationalization via Data Envelopment Analysis: An Empirical Examination. Journal of Supply Chain Management, v. 37, n. 3, p. 28-37, 2001.

PALADINI, E. Avaliação estratégica da qualidade. São Paulo: Atlas, 2002.

PIRES, S. Gestão da cadeia de suprimentos: conceitos, estratégias, práticas e casos. São Paulo: Atlas, 2004.

REA, L.; PARKER, R. Metodologia de pesquisa. São Paulo: Pioneira, 2002.
ROESCH, S. Projetos de estágio e de pesquisa em administração: guia para estágios, trabalhos de conclusão, dissertações e estudos de caso. São Paulo: Atlas, 1999.

ROSA, E.; SELLITTO, M.; MENDES, L. Avaliação multicriterial de desempenho e separação em aglomerados de fornecedores críticos de uma manufatura OKP. Produção, v. 16, n. 3, p. 413428, 2006.

SARKIS, J.; TALLURI, S. A Model for Strategic Supplier Selection. Journal of Supply Chain Management, v. 38, n. 1, p. 18-28, 2002.

SELLITTO, M. Medição e controle de desempenho estratégico em sistemas de manufatura. 2005. Tese (Doutorado em Engenharia de Produção) - Escola de Engenharia, Universidade Federal do Rio Grande do Sul, Porto Alegre, 2005.

SELLITTO, M.; RIBEIRO, J. Construção de indicadores para avaliação de conceitos intangíveis em sistemas produtivos. Gestão \& Produção, São Carlos, v. 11, n. 1, p. 75-90, 2004.

SLACK, N. Administração da produção. São Paulo: Atlas, 2002.

WEBER,C.; CURRENT, J.; BENTON, W. Vendor selection criteria and methods. European Journal of Operational Research, v. 50, n. 1, p. 2-18, 1991.

WERKEMA, M. C. Ferramentas estatísticas básicas para o gerenciamento de processos. Belo Horizonte: Fundação Christiano Ottoni, 1995.

YIN, R. Estudo de caso: planejamento e método. Porto Alegre: Bookman, 2001.

\section{SOBRE OS AUTORES}

\section{Diego Mondadori Rodrigues}

Universidade do Vale do Rio dos Sinos - Unisinos

Engenheiro de Produção

End.: Av. Unisinos 950, São Leopoldo - 93022-000 - RS

Tel.: (51) 3591-1122

E-mail: RodriguesDiegoMondadoriM@JohnDeere.com

\section{Miguel Afonso Sellitto}

Universidade do Vale do Rio dos Sinos - Unisinos

Professor e pesquisador do Programa de Pós-Graduação em Engenharia de Produção e Sistemas End.: Av. Unisinos 950, São Leopoldo - 93022-000 - RS

Tel.: (51) 3591-1122

E-mail: sellitto@unisinos.br 